\title{
The epidemiology of Salmonella Typhimurium in cattle: plasmid profile analysis of definitive phage type (DT) 204c
}

\author{
C. WRAY, I. M. MCLAREN and YVETTE E. JONES \\ Bacteriology Department, Central Veterinary Laboratory, New Haw, Addlestone, Surrey KT15 3NB
}

\begin{abstract}
During the period 1979-1991, Salmonella Typhimurium DT 204c was the cause of a major epidemic of salmonellosis in calves in the UK. Plasmid profile analysis of DT 204c isolates from England and Wales commenced in 1986 and isolates from all subsequent incidents were examined by this technique. Forty-three different plasmid profile types (PPTs) were detected, of which the commonest, designated type E, constituted 44.6$80.2 \%$ of the annual incidents during the study period. Some PPTs, e.g., F and P, were detected throughout most years of the study, whereas PPTs $O$ and 6 persisted for short periods. Until 1984, most isolates were resistant to neomycin, but the subsequent predominant PP type $\mathrm{E}$ was sensitive to this antibacterial agent. It was concluded that during the epidemic there was an evolution of new genotypes, of which only some persisted; again, antibacterial resistance genes may be acquired or lost. The study demonstrated the value of PP typing for epidemiological studies.
\end{abstract}

\section{Introduction}

During the period 1979-1991, Salmonella Typhimurium definitive type (DT) $204 \mathrm{c}$ was the cause of a major epidemic of salmonellosis in calves in the UK. All isolates of this phage type were resistant to at least one antimicrobial agent, with most isolates being multiply resistant to four or more antimicrobial agents. Previous studies have demonstrated the derivation of multiresistant strains of DT 204c from $S$. Typhimurium DT 204 by a process involving the acquisition of plasmids, transposons and carrier phages [1-4].

In the Central Veterinary Laboratory (CVL), plasmid profile analysis of DT $204 \mathrm{c}$ has been used to trace its spread and persistence in calf-rearing units [5-7]. Plasmid profile analysis of Typhimurium DT 204c commenced in 1986 and isolates from all subsequent incidents were examined by this technique. The purpose of the present communication is to describe the distribution of plasmid profile types (PPTs) among bovine isolates of DT 204c made in England and Wales during the period 1986-1993.

Received 10 May 1997; revised version accepted 1 Oct. 1997.

Corresponding author: Dr C. Wray.

\section{Materials and methods}

\section{Bacterial strains}

Isolates of $S$. Typhimurium DT 204c were submitted to the CVL for serological identification and were phage typed at the Laboratory of Enteric Pathogens, Central Public Health Laboratory, Colindale, London. Multiresistant strains were examined for plasmid content [5, 6]. Lysis in alkaline sodium dodecyl sulphate was followed by purification in phenol-chloroform and electrophoresis at $140 \mathrm{~V}$ for $3.5 \mathrm{~h}$ in agarose $0.7 \% \mathrm{w} / \mathrm{v}$. Gels were stained with ethidium bromide and photographed over UV light. The mol.wt of plasmids was determined approximately by comparison with standard plasmids of known mol.wt.

For plasmid profile typing each new profile was given a non-recognised-type (NRT) number and checked for reproducibility and stability. If the new plasmid profile type (PPT) was recognised in subsequent disease incidents, the NRT was then added to the typing scheme. With this method, 43 distinct PPTs have been recognised and each has been ascribed a letter $(\mathrm{A}-\mathrm{Z})$ or a number $(1-17)$.

\section{Sensitivity tests}

These were carried out as described previously [6]. Thus, a disk diffusion test was employed with Sensitest 
Agar (Oxoid, CM409) and antibiotic disks (Oxoid) containing the following antimicrobial agents: tetracycline $(\mathrm{T}, 10 \mu \mathrm{g}) ;$ neomycin $(\mathrm{N}, 10 \mu \mathrm{g})$; ampicillin (A, $10 \mu \mathrm{g}$ ); furazolidone (Fr, $15 \mu \mathrm{g}$ ); sulphamethoxazole/ trimethoprim (Sx, $25 \mu \mathrm{g}$ ); chloramphenicol (C, $10 \mu \mathrm{g}$ ); streptomycin (S, $25 \mu \mathrm{g}$ ); sulphonamides ( $\mathrm{Su}, 500 \mu \mathrm{g}$ ) and apramycin (Ap, $15 \mu \mathrm{g})$. A zone diameter of $<13 \mathrm{~mm}$ was recorded as resistant.

\section{Results}

\section{Incidence of Typhimurium DT 204c}

During the period 1979-1993, 4577 incidents of DT 204c infection were reported (Table 1), most of which (95\%) occurred in cattle, with $80.2 \%$ in calves. The epidemic reached its peak in 1985 when 811 incidents were reported; it gradually decreased until in 1992 only 45 incidents were reported. Two hundred and twenty- two incidents were recorded in other species of farm animals.

\section{Antimicrobial resistance pattern}

Table 2 shows the antimicrobial resistance patterns of isolates of DT 204c during the period 1982-1993. All the isolates showed resistance to sulphonamides, tetracyclines, ampicillin and trimethoprim and so the last three antimicrobial agents have not been included in Table 2. Until 1984 most strains showed resistance to neomycin, but the number of resistant strains decreased so that in 1991 no isolate with resistance to this agent was detected. No strain was resistant to apramycin in 1982, but since then the number of apramycin-resistant strains increased to $34.8 \%$ in 1986 and then declined gradually until 1992 when only one apramycin-resistant isolate was received. However, in $1993,6.8 \%$ and $11.5 \%$ of isolates showed resistance to

Table 1. The incidence of $S$. Typhimurium DT $204 \mathrm{c}$ in cattle and other species of farm animals during the period 1979-1993

\begin{tabular}{|c|c|c|c|c|c|c|}
\hline \multirow{3}{*}{$\frac{\text { Year }}{1979}$} & \multicolumn{5}{|c|}{ Number of incidents in } & \multirow{3}{*}{$\frac{\begin{array}{c}\text { Total number of } \\
\text { incidents }\end{array}}{48}$} \\
\hline & \multicolumn{2}{|c|}{ Calves* } & \multicolumn{2}{|c|}{ Adult cattle* } & \multirow{2}{*}{$\begin{array}{c}\begin{array}{c}\text { Other reportable } \\
\text { animals }\end{array} \\
3\end{array}$} & \\
\hline & 42 & (93) & 3 & $(7)$ & & \\
\hline 1980 & 126 & (83) & 25 & (17) & 13 & 164 \\
\hline 1981 & 81 & $(85)$ & 14 & (15) & 7 & 102 \\
\hline 1982 & 72 & (86) & 11 & (14) & 2 & 85 \\
\hline 1983 & 362 & (92) & 31 & $(8)$ & 18 & 411 \\
\hline 1984 & 574 & (90) & 61 & (10) & 23 & 658 \\
\hline 1985 & 656 & $(85)$ & 119 & (15) & 36 & 811 \\
\hline 1986 & 468 & (83) & 113 & (17) & 36 & 617 \\
\hline 1987 & 295 & (80) & 72 & (20) & 14 & 381 \\
\hline 1988 & 297 & (81) & 71 & (19) & 13 & 381 \\
\hline 1989 & 224 & (83) & 45 & (17) & 23 & 292 \\
\hline 1990 & 270 & (78) & 75 & (22) & 19 & 364 \\
\hline 1991 & 107 & (78) & 30 & (22) & 8 & 145 \\
\hline 1992 & 35 & (84) & 7 & (16) & 3 & 45 \\
\hline 1993 & 62 & $(90)$ & 7 & (10) & 4 & 73 \\
\hline All & 3671 & $(80.2)$ & 684 & $(14.0)$ & 222 & 4577 \\
\hline
\end{tabular}

* In parentheses, percentage of bovine incidents.

${ }^{\dagger}$ Sheep, pigs and poultry.

Table 2. Resistance to antimicrobial agents of $S$. Typhimurium DT 204c isolates from all animal species received at CVL from 1982 to 1993

\begin{tabular}{lccrrrr}
\hline \multicolumn{7}{c}{ Number (\%) of isolates resistant to } \\
Year & \multicolumn{7}{c}{$\mathrm{N}^{*}$} & $\mathrm{Fr}$ & \multicolumn{1}{c}{$\mathrm{C}$} & $\mathrm{S}$ & $\mathrm{Su}$ & \multicolumn{1}{c}{ Ap } \\
\hline 1982 & $111(90.2)$ & $0(0)$ & $121(98.4)$ & $40(32.5)$ & $123(100)$ & $0(0)$ \\
1983 & $619(98.1)$ & $1(0.2)$ & $623(98.7)$ & $217(34.4)$ & $629(99.7)$ & $12(1.9)$ \\
1984 & $962(97.5)$ & $2(0.2)$ & $980(99.2)$ & $501(50.7)$ & $983(99.5)$ & $68(6.9)$ \\
1985 & $835(77.7)$ & $1(0.1)$ & $1060(98.7)$ & $591(55.0)$ & $1071(99.7)$ & $262(24.3)$ \\
1986 & $302(48.6)$ & $13(2.1)$ & $615(99.0)$ & $436(70.2)$ & $619(99.7)$ & $216(34.8)$ \\
1987 & $120(22.5)$ & $2(0.4)$ & $532(99.6)$ & $152(28.5)$ & $534(100)$ & $112(21.0)$ \\
1988 & $64(14.4)$ & $1(0)$ & $432(97.5)$ & $148(33.4)$ & $443(100)$ & $134(30.2)$ \\
1989 & $25(5.5)$ & $1(0.2)$ & $407(89.8)$ & $120(26.5)$ & $446(98.5)$ & $95(21.0)$ \\
1990 & $7(1.4)$ & $4(0.8)$ & $482(94.1)$ & $140(27.3)$ & $498(97.3)$ & $88(17.2)$ \\
1991 & $0(0)$ & $0(0)$ & $210(96.8)$ & $55(25.3)$ & $216(99.5)$ & $22(10.1)$ \\
1992 & $4(6)$ & $0(0)$ & $62(95.3)$ & $14(21.5)$ & $64(98.5)$ & $1(1.5)$ \\
1993 & $10(6.8)$ & $0(0)$ & $136(91.9)$ & $72(48.7)$ & $148(100)$ & $17(11.5)$ \\
\hline
\end{tabular}

NB: All isolates were resistant to ampicillin, tetracycline and trimethoprim.

* For antibiotic designations, see Materials and methods. 
neomycin and apramycin, respectively. Furazolidone resistance was seldom encountered. Resistance to streptomycin fluctuated between $21.5 \%$ in 1992 and $70.2 \%$ in 1986 .

\section{Plasmid profile analysis}

Table 3 shows the PPTs identified among isolates of DT 204c received at the CVL during the period 19861993. Type E was the dominant profile, and constituted $44.6-80.2 \%$ of the annual incidents during the period of study. The profiles $\mathrm{F}$ and $\mathrm{P}$ were detected throughout most years of the study, whereas type $O$ and type 6 profiles persisted for relatively short periods. Altogether, 43 different profiles were detected. The plasmid profiles of the more common types are shown (Fig. 1).

Table 4 shows the antimicrobial resistance pattern of the more common profiles; PP types $E$ and $F$ were both sensitive to neomycin, but the latter (including $E^{*}$ ) was resistant to apramycin. Type 9 was sensitive to chloramphenicol; the major difference of the more common profiles was in neomycin and apramycin resistance.

\section{Discussion}

During the period $1979-1993$ there were 4355 reported incidents of Typhimurium DT 204c in cattle, of which $84 \%$ occurred in calves. However, the number of reported incidents is likely to be an underestimate of the true incidence of infection, because previous studies on calf-rearing units found that DT $204 \mathrm{c}$ was frequently detected in the absence of clinical disease and would not have been reported under the Zoonoses Order [9]. The rapid spread of this phage type in calves is primarily attributable to the marketing system whereby surplus dairy calves enter the market-dealer network. Previous studies have shown that many markets, transport vehicles and dealers' premises were contaminated with DT 204c [10] and there are many opportunities for calves to be infected either directly or indirectly. The organism can persist for long periods in the environment of rearing farms [7] and calves may, therefore, be infected after arrival. A total of $16 \%$ of the incidents occurred in adult cattle, but with the possible exception of the period 1984-1988, they are unlikely to provide a significant reservoir. Indeed, several studies have shown that Typhimurium infection seldom persists for more than 3-6 months in adult cattle [11].

DT $204 \mathrm{c}$ constituted $38.1 \%$ of the incidents caused by serotype Typhimurium during the period 1979-1993 and plasmid profile analysis was used to study the epidemiology of phage type DT 204c from 1986 onwards. Although PP type E predominated and constituted $44-81 \%$ of all isolates, 42 other PPTs were detected. The descriptive epidemiology of some of these different types has been described previously $[6,7]$ and it is of interest to note that type $O$, which was relatively frequent during 1986 , was seldom detected thereafter. Again, types A, B, J, 2, 6 and 9 were associated with a number of incidents and then rarely detected subsequently. Thus, during the epi-

Table 3. Plasmid profile types (PPTs) of $S$. Typhimurium DT 204c isolates from cattle in England and Wales, 1986-1993

\begin{tabular}{lcccccc}
\hline Year & \multicolumn{7}{c}{ Most common PPT in year: number (\%) of incidents } & Other types \\
\hline $1986^{* *}$ & $\mathbf{E}$ & $\mathbf{0}$ & $\mathbf{P}$ & $\mathbf{B}$ & $\mathbf{F}$ & $14^{\dagger}$ \\
& 95 & 37 & 20 & 11 & 10 & 40 \\
& $(44.6)$ & $(17.4)$ & $(9.4)$ & $(5.2)$ & $(4.7)$ & $(18.7)$ \\
1987 & $\mathbf{E}$ & $\mathbf{P}$ & $\mathbf{A}$ & $\mathbf{2}$ & $\mathbf{F}$ & $17^{\dagger}$ \\
& 151 & 21 & 17 & 15 & 14 & 82 \\
& $(50.3)$ & $(7.0)$ & $(5.7)$ & $(5.0)$ & $(4.7)$ & $(27.3)$ \\
1988 & $\mathbf{E}$ & $\mathbf{F}$ & $\mathbf{6}$ & $\mathbf{A}$ & $\mathbf{P}$ & $7^{\dagger}$ \\
& 142 & 52 & 10 & 7 & 4 & 32 \\
& $(57.7)$ & $(21.1)$ & $(4.1)$ & $(2.8)$ & $(1.6)$ & $(13.0)$ \\
1989 & $\mathbf{E}$ & $\mathbf{F}$ & $\mathbf{9}$ & $\mathbf{P}$ & $\mathbf{6}$ & $12^{\dagger}$ \\
& 160 & 20 & 15 & 11 & 9 & 41 \\
& $(62.5)$ & $(7.8)$ & $(5.9)$ & $(4.3)$ & $(3.5)$ & $(16.0)$ \\
1990 & $\mathbf{E}$ & $\mathbf{F}$ & $\mathbf{E}$ & $\mathbf{2}$ & $\mathbf{P}$ & $12^{\dagger}$ \\
& 164 & 25 & 12 & 9 & 5 & 52 \\
& $(67.5)$ & $(10.2)$ & $(4.9)$ & $(3.7)$ & $(2.1)$ & $(19.4)$ \\
1991 & $\mathbf{E}$ & $\mathbf{7}$ & $\mathbf{F}$ & $\mathbf{1 6}$ & $\mathbf{P}$ & $4^{\dagger}$ \\
& 83 & 8 & 4 & 3 & 1 & 4 \\
& $(80.1)$ & $(7.7)$ & $(3.8)$ & $(2.9)$ & $(0.9)$ & $(3.8)$ \\
1992 & $\mathbf{E}$ & $\mathbf{F}$ & $\mathbf{2}$ & 7 & 7 & $1^{\dagger}$ \\
& 26 & 5 & 4 & 1 & 1 & 1 \\
& $(68.4)$ & $(13.2)$ & $(10.5)$ & $(2.6)$ & $(2.6)$ & $(2.6)$ \\
1993 & $\mathbf{E}$ & $\mathbf{F}$ & $\mathbf{P}$ & $\mathbf{2}$ & $\mathbf{1 1}$ & $1^{\dagger}$ \\
& 49 & 5 & 3 & 2 & 1 & 1 \\
& $(80.2)$ & $(8.1)$ & $(4.9)$ & $(3.2)$ & $(1.6)$ & $(2.6)$ \\
\hline
\end{tabular}

$\mathrm{E}^{*}$, resistant to apramycin.

${ }^{* *}$ Data for Aug.-Dec. 1986 only.

tUpper figure is total number of less frequent PPTs detected in year. 


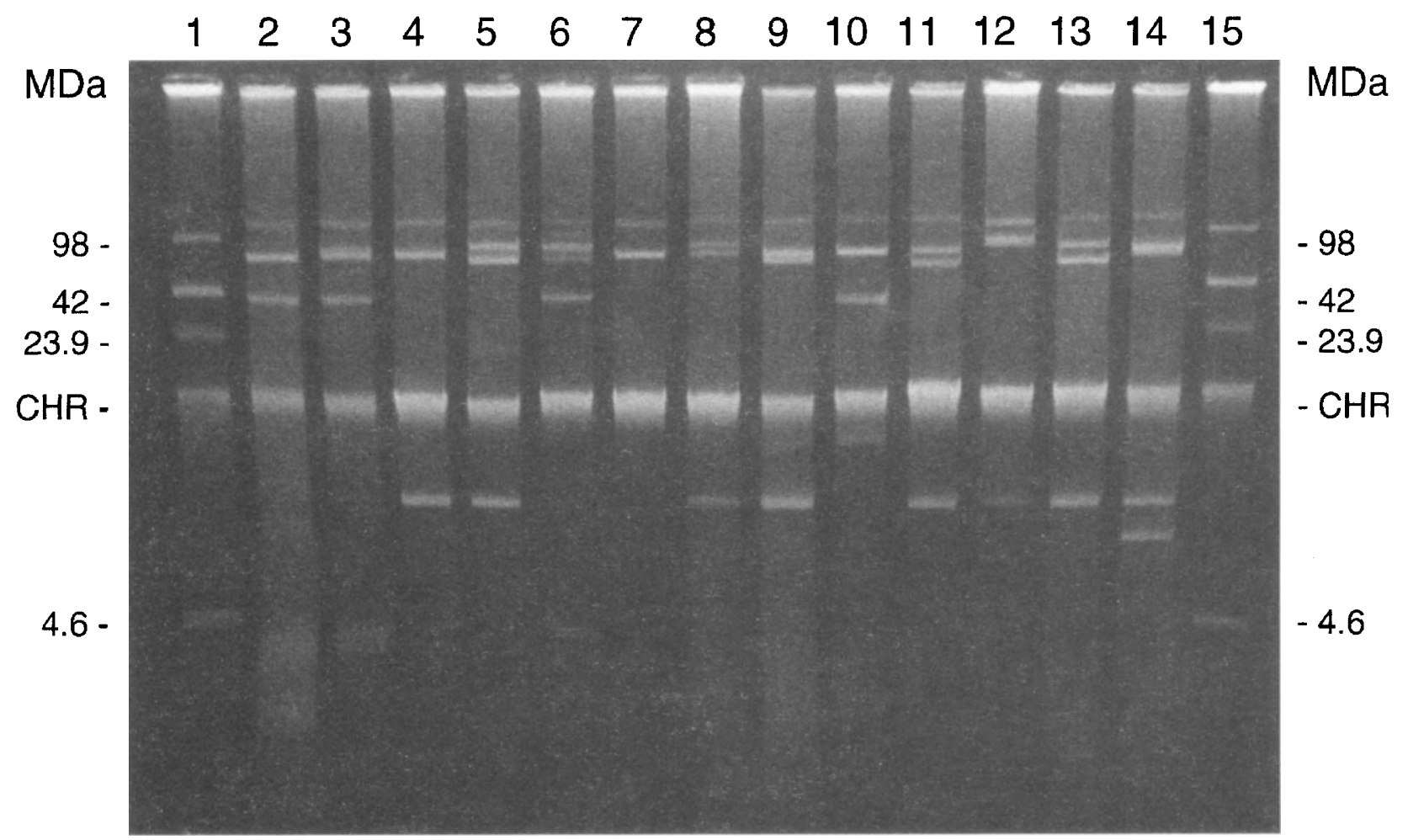

Fig. 1. Common plasmid profile types (PPTs) detected among isolates of Typhimurium DT 204c. Lanes 2-14, PPTs A, $\mathrm{B}, \mathrm{E}, \mathrm{F}, \mathrm{O}, \mathrm{P}, 1,2,6,7,9,11$, and 16, respectively; 1 and 15, mol.-wt. markers derived from 39R861. CHR = chromosomal DNA.

Table 4. Antibacterial resistance patterns of plasmid profile types (PPTs) of $S$. Typhimurium DT 204c

\begin{tabular}{lcccccc}
\hline & \multicolumn{6}{c}{ Resistance to antimicrobial agent* } \\
\cline { 2 - 7 } PPT & N & Fr & C & S & Su & Ap \\
\hline A & R & - & R & R & R & - \\
B & R & - & R & R & R & - \\
E & - & - & R & R & R & - \\
E* & - & - & R & R & R & R \\
F & - & - & R & R & R & R \\
O & R & - & R & R & R & R \\
P & - & - & R & R & R & - \\
2 & - & - & R & R & R & - \\
6 & R & - & R & R & R & R \\
9 & - & - & - & R & R & R \\
\hline
\end{tabular}

$\mathrm{E}^{*}$, Resistant to apramycin; $\mathrm{R}$, resistant. All isolates were resistant to ampicillin, tetracyline and trimethoprim.

${ }^{*}$ For antibiotic designations, see Materials and methods.

demic there was an evolution of new genotypes, not all of which persisted. This was also clearly demonstrated in the case of antibiotic resistance, when new resistance genes were acquired, but equally important was the loss of resistance genes, especially those coding for some of the different aminoglycoside resistances. Similarly, PT 29 , which was the cause of a major Typhimurium epidemic in calves in the $1960 \mathrm{~s}$, rapidly acquired antimicrobial resistance genes, but recent isolates of this phage type, although infrequent, seldom show resistance. In some Salmonella serotypes, e.g., Dublin, plasmid resistance genes appear unstable and may be either lost on subculture or incorporated into the chromosome [12]. Similar chromosomal integration of resistance genes has also been observed in multi-resistant Typhimurium DT 104 [13] currently epidemic in man [14] and cattle [15, 16] in England and Wales. The factors that lead to the loss of genes are largely unknown, although it has been suggested that the possession of plasmids may present additional metabolic burdens on a bacterium.

During the epidemic a constant evolution of PPTs occurred, some of which persisted in the calf population for long periods. Whether these types possessed a selective advantage which enabled them to survive in a particular niche is not known. In addition to the acquisition of plasmids, which was accompanied by changes in antibiotic resistance pattern in some cases, other metabolic changes are likely to occur and in enterobacteria virulence determinants are often linked to other genes, e.g., in Escherichia coli raffinose fermentation and the $\mathrm{F} 4$ antigen, colicine $\mathrm{V}$ and iron sequestration $[17,18]$. Similarly, the maltose regulon of Vibrio cholerae has been shown to affect the production and secretion of virulence factors [17]. Whether the antibiotic resistance gave a selective advantage is unknown, but serotypes Agona and Hadar, which caused epidemics in poultry and spread into man, did not develop resistance. Likewise, Dublin, which occurs predominantly in cattle and is subject to the same antimicrobial selection pressures 
as Typhimurium, rarely develops antimicrobial resistance in the UK. In 1990, government regulations to control calf marketing and improvements in husbandry contributed to the end of the DT 204c epidemic.

The study has clearly demonstrated the value of plasmid profile typing in studying the epidemiology of DT $204 \mathrm{c}$ in cattle. However, it should be noted that this method is applicable only to those serotypes and phage types that possess plasmids with a range of mol. wts. In the present epidemic of multiply resistant DT 104, most isolates are characterised by a single plasmid of c. $60 \mathrm{MDa}$ [14] and, for meaningful epidemiological investigations of that phage type, methods of subdivision within the phage type are required.

We thank Dr B. Rowe, Dr E. J. Threlfall and Mrs L. Ward of the Laboratory of Enteric Pathogens, CPHL, Colindale for help in various ways and for phage typing isolates. The work was funded by Chief Scientist Group, Ministry of Agriculture, Fisheries and Food.

\section{References}

1. Threlfall EJ, Ward LR, Ashley AS, Rowe B. Plasmid-encoded trimethoprim resistance in multiresistant epidemic Salmonella tvphimurium phage types 204 and 193 in Britain. BMJ 1980; 280: $1210-1211$

2. Willshaw GA, Threlfall EJ, Ward LR, Ashley AS, Rowe B. Plasmid studies of drug-resistant epidemic strains of Salmonella typhimurium belonging to phage types 204 and 193. $J$ Antimicrob Chemother 1980; 6: 763-773.

3. Threlfall EJ, Ward LR, Rowe B. The use of phage typing and plasmid characterization in studying the epidemiology of multiresistant Salmonella typhimurium. In: Russell AP, Quesnel, LB (eds) Antibiotics: methods of assessing antimicrobial resistance and the occurrence of resistance. SAB Technical Series. London, Academic Press. 1983: 285-297.

4. Threlfall EJ, Rowe B, Ferguson JL, Ward LR. Characterization of plasmids conferring resistance to gentamicin and apramycin in strains of Salmonella typhimurium phage type 204c isolated in Britain. J Hyg 1986; 97: 419-426.

5. Wray C, McLaren I, Parkinson NM, Beedell Y. Differentiation of Salmonella typhimurium DT204c by plasmid profile and biotyping. Vet Rec 1987; 121: 514-516.

6. Wray C, Todd N, McLaren I, Beedell Y, Rowe B. The epidemiology of salmonella infection in calves: the role of dealers. Epidemiol Infect 1990; 105: 295-305.

7. McLaren IM, Wray C. Epidemiology of Salmonella typhimurium infection in calves: persistence of salmonellae on calf units. Vet Rec 1991; 129: 461-462.

8. Wray C, Beedell YE, McLaren IM. A survey of antimicrobial resistance in salmonellae isolated from animals in England and Wales during 1984-1987. Br Vet $J$ 1991; 147: 356-369.

9. Wray C, Todd JN, Hinton M. Epidemiology of Salmonella typhimurium infection in calves: excretion of $S$. typhimurium in the faeces of calves in different management systems. Vet Rec 1987; 121: 293-296.

10. Wray C, Todd N, McLaren IM, Beedell YE. The epidemiology of salmonella in calves: the role of markets and vehicles. Epidemiol Infect 1991; 107: 521-525.

11. Wray C, Sojka WJ. Reviews of the progress of dairy science: bovine salmonellosis. J Dairy Sci 1977; 44: 383-425.

12. Woodward MJ, McLaren I, Wray C. Genetic evidence for a chromosomally integrated multiresistance plasmid in Salmonella dublin. J Med Microbiol 1989; 28: 205-210.

13. Threlfall EJ, Frost JA, Ward LR, Rowe B. Epidemic in cattle and humans of S. typhimurium DT 104 with chromosomally integrated multiple drug resistance. Vet Rec 1994; 134: 577.

14. Wall PG, Morgan D, Lamden $\mathrm{K}$ et al. A case control study of infection with an epidemic strain of multiresistant Salmonella typhimurium DT 104 in England and Wales. Commun Dis Rep CDR Review 1994; 4: R130-R135.

15. Anon. Salmonella in Animal and Poultry Production 1992. Ministry of Agriculture, Fisheries and Food, Welsh Office, Agriculture Department, Scottish Office, Agriculture and Fisheries Department. 1993.

16. Wray C. Davies RH. A veterinary view of salmonella in farm animals. PHLS Microbiol Digest 1996; 13: 44-48.

17. Smith HW, Parsell Z. Transmissible substrate-utilizing ability in enterobacteria. J Gen Microbiol 1975; 87: 129-140.

18. Smith HW. A search for transmissible pathogenic characters in invasive strains of Escherichia coli: the discovery of a plasmidcontrolled toxin and a plasmid-controlled lethal character closely associated, or identical, with colicine V. $J$ Gen Microbiol 1974; 83: 95-111.

19. Lang H, Jonson G, Holmgren J, Palva ET. The maltose regulon of Vibrio cholerae affects production and secretion of virulence factors. Infect Immun 1994; 62: 4781-4788. 